\title{
AROUSING FEAR IN DENTAL HEALTH EDUCATION*†
}

\author{
By Don P. Haefner, Ph.D.**
}
Now, there seem to be some situations in which it is proper to frighten people into appropriate behavior for achieving health.

Although the term health education is relatively recent in origin, efforts have been made for centuries to get people to take appropriate actions for ensuring length of years and soundness of body and spirit. How best to persuade them to do so is a fundamental issue, yet unresolved, with which health educators must deal. As Galdston puts it, "It has always been taken for granted that man's behavior is motivated, and that its motivation can be influenced. But neither the mainspring of motivation nor the means by which it could be influenced have been consistently agreed upon, or defined."

Throughout the centuries, the rationalistic and antirationalistic viewpoints concerning the basis for man's actions have vied for supremacy. Depending largely on historical events, first one and then the other has been dominant. As society's philosophical outlook on the determinants of behavior has changed, the practices of health education have shown similar fluctuations.

In the fairly recent past, efforts to motivate the public toward seeking better health shifted in turn from emphasis on the use of fear to an approach that stressed the arousal of positive emotions, and then to a highly rationalistic phase which avoided any sort of emotional arousal. More recently, health workers have shown renewed interest in the role of emotional factors in determining health behavior. The interest in emotional factors seems to have developed from the insights of current psychiatry and the vaunted successes of advertising agencies in the use of such insights to sell merchandise. All of the various orientations cannot be equally correct in their viewpoints, however, since they flatly contradict each other's basic premises. In order to provide a firm basis for planning programs, research is needed to determine the extent to which various educational approaches can influence people to take appropriate health action. Since human beings often show diverse reactions to the same stimuli, it is rather unlikely that any single approach will be universally superior. Research, hopefully, will be able to specify the conditions under which a particular motivational approach is most effective.

In the early 1950's, Janis and Feshbach ${ }^{2}$ performed a pioneering experimental study of the effect of the arousal of fear on attitudes toward and behavior concerning dental health. These two investigators were interested to learn whether making people anxious about dental problems might produce adverse effects that would interfere with influencing them. In the study, groups

\footnotetext{
*Presented at the 92nd Annual Meeting, American Public Health Association, October 7, 1964. tInvestigation supported by Public Health Service Grant CH-00044, Division of Community Health Services.

* Associate Professor, School of Public Health, University of Michigan, Ann Arbor.
} 
of high school freshmen in Greenwich, Connecticut, listened to a tape-recorded lecture on oral hygiene that was illustrated by slides. Three forms of the lecture, designed to induce strong fear, moderate fear and minimal fear, respectively, were presented. All three versions contained the same essential information about the causes of dental caries and made the same series of recommendations as desirable for the practice of oral hygiene. The lectures differed markedly, however, in the amount of fear-arousing material that each presented.

Janis and Feshbach found, on one hand, that the message arousing strong fear elicited the most favorable appraisals of the communication by the audience and proved equally as effective as the other versions in teaching factual information. Quite different results were obtained, on the other hand, concerning acceptance of the message's recommendation. The minimal-fear appeal proved far more effective than the other two messages in persuading students to adopt the recommended practices of oral hygiene, whereas the message that aroused strong fear was the least effective. The same finding was demonstrated when students subsequently were asked to react to a statement which contradicted the message's emphasis on the use of the proper type of toothbrush. Minimal fear elicited the most resistance to the counter propaganda and strong fear, the least resistance.

The findings received considerable attention which led, not infrequently, to uncritical acceptance of the idea that the less fear aroused, the better. Detailed scrutiny revealed some methodological limitations, however, that could have affected the outcome. The researchers failed to control for a number of variables that might have worked in favor of the message which evoked minimal fear. All of the criteria of the effectiveness of the communication were based upon a self-report of the audience, a procedure that is open to distortion.

Subsequent research on the arousal of fear has yielded mixed results. Minimal arousal of fear more recently has been found to be more effective than strong arousal of fear in changing attitudes and behavior in some instances, ${ }^{3,4,5}$ less effective than in other instances ${ }^{6, T}$ and no different in effectiveness in still another. ${ }^{\circ}$

In spite of the subsequent findings, even recent reviews of the literature contain statements such as the one which follows: “. . . it seems reasonable to conclude that fear is an unsatisfactory motivation to employ in public health education. Strong-fear appeals are likely to produce avoidance, hostility, denial, suppression, and behavioral responses based upon irrational considerations. The tendency of individuals to avoid anxiety-arousing issues leads to maladaptive behavior and to failure to adopt the desired practices."' In view of the mixed results that have been cited, it does not appear justifiable to reach such a one-sided conclusion on the use of fear. It appears, rather, that the the essential problem to be solved, one posed by Feshbach ${ }^{10}$ a few years ago, is the specification of the conditions under which the arousal of fear facilitates desired behavioral changes and the conditions under which it interferes with such changes.

As a first step in this determination, the decision was made both to repeat and extend the original study of Janis and Feshbach. ${ }^{2}$ This new approach used the original strong-fear and minimal-fear messages that Janis and Feshbach designed so that the generalizability of their findings could be assessed. The experiment, however, employed revisions of these two messages that were equated for a variety of factors. The revisions were made in order to investigate the possibility that the outcome of the earlier study was caused, at least in part, 
by the operation of uncontrolled variables rather than by the inherent superiority of arousing low fear as a motivating device. Behavioral criteria of the effectiveness of the message were employed to supplement the self-report measures used by Janis and Feshbach.

The study sought to determine the effects of messages designed to elicit different levels of fear about dental problems on a number of outcomes. The outcomes included:

(1) emotional reactions to the message,

(2) evaluation of the message,

(3) information learned from the message,

(4) reported practices of dental hygiene,

(5) reactions to counterpropaganda,

(6) beliefs concerning the characteristics of the proper type of toothbrush,

(7) actual behavior with respect to

(a) obtaining a free toothbrush and

(b) obtaining a free pamphlet on dental hygiene.

Subjects of the experiment now to be reported were 256 ninth grade students in the public school system of Ypsilanti, Michigan. The students in the study were drawn from health classes in the city's two public junior high schools. The schools were of approximately equal size.

Five sessions were held in which the following procedure was utilized:

(1) One week prior to hearing the communication, the students in health classes completed a questionnaire about their attitudes, beliefs and behavior concerning various health topics including dental hygiene. Each student then was assigned randomly to one of four experimental groups. The four groups were well equated for age, sex and IQ.

(2) A week later, each of the experimental groups listened during health class to a different one of the four tape-recorded communications, supplemented by slides. The communications included (a) Janis and Feshbach's original strongfear message, (b) Janis and Feshbach's original minimal-fear message, (c) a revised strong-fear message and (d) a revised minimal-fear message.

The revised messages, as has been stated, were modifications of those employed by Janis and Feshbach. They were equated on several potentially important factors that had been left uncontrolled in their earlier experiment. Examples of the variables were the number of words, number of slides, personalized references, and the extent of explicit reassurance concerning the efficacy of the recommended practices of oral hygiene in minimizing dental disease. Students then completed a questionnaire designed to determine the degree of fear evoked by the message, their appraisal of the communication, and the amount of information they remembered from it.

(3) A week after hearing one of the four communications, each student completed a questionnaire concerning (a) his current practice of dental hygiene, (b) his beliefs concerning the "proper" type of toothbrush to use, and (c) his reactions to a brief statement of counterpropaganda which contradicted a major theme of the prior communication about the importance of using the proper kind of toothbrush.

(4) Three weeks after the session on communication, students were given an opportunity to obtain a free toothbrush by going to a designated room. Those who did so had to choose from among five different brushes, only one of which possessed all of the characteristics recommended in the communication. 
(5) Four weeks after hearing the communication, the students were given the opportunity to go to a designated room and obtain a free pamphlet containing additional information about dental hygiene.

To summarize the procedure briefly, four groups of high school freshmen each heard a different, recorded talk on dental health education. The effects of each strong-fear message then were compared to those of the appropriate message which aroused minimal fear. Outcomes were examined that ranged from emotional reactions evoked by each message to reported practices of dental hygiene, resistance to subsequent counterpropaganda, and response to an offer of a free toothbrush and dental pamphlet.

The findings of the study proved similar to those of Janis and Feshbach in some respects. For one thing, each message designed to arouse strong fear, did, in fact, evoke significantly more fear in the audience than did its counterpart that was designed to arouse minimal fear. The finding was the same for both the original and the revised versions of the talk (Table 1). The audience's immediate reactions to the messages were similar to those obtained by Janis and Feshbach, inasmuch as the strong-fear communication consistently elicited more favorable ratings than did the comparable minimal-fear message on such items as interest, ease of paying attention, and even the speaker's voice, although the same person had narrated all scripts! (Table 2). As in the Janis-Feshbach study, the strong-fear and minimal-fear groups acquired comparable amounts of information and showed similar beliefs concerning the characteristics of a proper toothbrush.

The present study obtained far different results concerning changes in reported toothbrushing from those of the earlier experiment. In this later study, arousal of strong fear proved to be significantly more effective than minimal fear in persuading students to change their habits of toothbrushing (Table 3), a result exactly opposite to that previously obtained by Janis and Feshbach. Reactions to counterpropaganda that contradicted the message's emphasis on using the proper type of toothbrush also were unlike those obtained by Janis and Feshbach. The four experimental groups in the present study all responded very similarly to the counterpropaganda, whereas the earlier study had found the minimal-fear group to be much more resistant than the strong-fear group. With respect to the additional behavioral criterion of obtaining a free pamphlet on dental hygiene, strong fear was significantly more effective than minimal fear at one school and equally as effective at the other one (Table 4). A similar result in favor of strong fear was found with regard to the number of students who obtained a free toothbrush. Although consistent with the other findings, this finding could not be regarded as a fully valid criterion because of the administrative problems connected with the distribution of the toothbrushes.

The effects of the messages on acceptance of their recommendations were quite discrepant with those previously obtained by Janis and Feshbach. Taken by itself, the finding that the revised strong-fear message was more effective than the revised minimal-fear appeal was not especially surprising. As was stated earlier, it seemed possible that several variables which were uncontrolled in the earlier study could have influenced the outcome. The results for the revised messages, taken alone, could be interpreted as an indication that Janis and Feshbach's original finding was an artifact rather than a difference produced by the superiority of arousing minimal fear per se. The findings obtained were true, however, not only for the revised messages, but also for 
the original messages of Janis and Feshbach. That occurrence was quite unexpected and initially somewhat perplexing.

Further analysis revealed a likely explanation for the difference in outcomes of the two studies. The explanatory factor seemed to be the nature of the target-audience utilized in each instance. Although both the original study. and the present one were performed with students in the ninth grade, the nature of the two communities from which the students came was noticeably different. The students in the Janis-Feshbach study were from a very well-to-do suburban community, whereas those in the present study came from an industrial town. In view of the previous findings, ${ }^{11}$ it seemed possible that differences in the social background of the two groups might have contributed to the divergent results.

To check this reasoning, an additional analysis was performed. Information had been collected concerning certain characteristics of the students engaged in the present experiment. One such factor was the occupation of the head of household which was included to provide a crude index of social status. Comparisons were made of the way in which responses to the strongfear messages and minimal-fear messages were related to social status as measured by parental occupational level (Table 5).

Minimal arousal of fear proved somewhat more effective than arousal of strong fear in changing patterns of toothbrushing of children of relatively high social status. This finding accorded, on the whole, with that of the original Janis-Feshbach experiment, although the difference was not so pronounced in their study. Moving down the scale of social status, however, the reverse held true when the lowest level of social status was reached, a strong-fear message was more effective than a minimal-fear message in eliciting conformity to the recommended practices of oral hygiene.

The groups in the present study were heavily weighted with students of middle and low social status. This factor apparently accounted for the greater effectiveness of arousal of strong fear in the present study. Janis and Feshbach's opposite result in favor of minimal fear seems attributable to their utilization of an audience predominantly of high social status.

The findings of the present study have helped to increase understanding of the conditions under which the arousal of fear is more effective or less effective as a motivating device. The finding that the level of social status of the audience was a significant determinant of response to fear-arousing messages requires confirmation through further research. If supported, it would appear to have a rather straightforward implication for dental health education in the classroom. The results also have raised other issues whose solution will require additional research. For instance, how can one best explain the finding that children of higher social status responded more favorably to a message arousing mild fear while those of lower social status reacted more favorably to a strong appeal to fear? A number of factors associated with the level of social status come to mind. Sociological considerations, such as different child-training practices, might account satisfactorily for the result. On the other hand, psychological factors such as differential utilization of various mechanisms of defense against threat might supply a more adequate explanation. Whichever explanatory variables are operative and how they are interrelated remain to be demonstrated.

Information also is needed about other types of factors that influence reactions to messages which arouse concern over disease. Certain beliefs about 
health, for example, have been found previously to be linked with health action." The extent to which such beliefs are changed by arousing different degrees of fear and, in turn, influence overt behavior, has to be ascertained. It would seem to be desirable to study the consequences of arousing fear over the more threatening health problems than those of dental disease, for example, problems such as heart disease, tuberculosis or cancer. Such systematic research eventually should make it possible to select an educational approach with confidence that it will be optimally effective for a given audience and a particular health topic.

TABLE I

Self-Report Measures of Fear Aroused as a Consequence of Hearing the Talk

\section{Measure}

A) Degree to which students felt worried or concerned over both tooth decay and gum disease.

B) Degree to which students felt upset or uncomfortable from hearing the illustrated talk.

C) Number of the following adjectives checked by students as descriptive of how they felt during the talk:

1. Afraid, fearful, frightened, horrified.

2. Anxious, jittery, nervous, uneasy.

\section{Outcome}

For each measure, Strong Fear group greater than Minimal Fear group, $P$ less than, $05^{*}$ True both for the groups hearing the original Janis-Feshbach communications and those hearing the revised communications.

"All probability values in this table are 1-tail, because of the directional prediction that the Strong-Fear messages would elicit greater fear than the Minimal-Fear messages.

TABLE 2

Evaluation of the Communication by the Experimental Groups

\section{Content of Item}

A) How good a job the talk did in teaching students the "how and why of toothbrushing"

B) How much of the talk was interesting

C) Whether or not the talk should be presented to all high school students in Michigan

D) Quality of the speaker's voice

E) Quality of the slides shown on the s:reen

F) How often the student's nind wandered

G) Ease of paying attention to the speaker while the talk was being given

\section{Outcome}

For each item, the Strong-Fear group reacted more favorably than its Minimal-Fear counterpart. True both for the groups hearing the original Janis-Feshbach communications and those hearing the revised communications.

All differences significant beyond $\mathrm{P}$ less than .05 level except for Item $G$ ease of paying attention, whose $\mathrm{P}$-value was just at the $\mathrm{P}=$ .10 level.

TABLE 3

Effect of Talk on Conformity to

Recommended Dental Hygiene Practices

Summary of Analysis of Variance

\section{Variable}

A) Strong vs. Minimal Fear

B) Original vs. Revised Message

C) Interaction between Fear Level and Version of Message
F-ratio

5.97

.00

.93

$$
\text { P-value }
$$

less than $.025,1$ and 252 d.f.

Not signif.

Not signif. 
TABLE 4

Percentage of Each Group Obtaining Free Dental Hygiene Pamphlet

School A
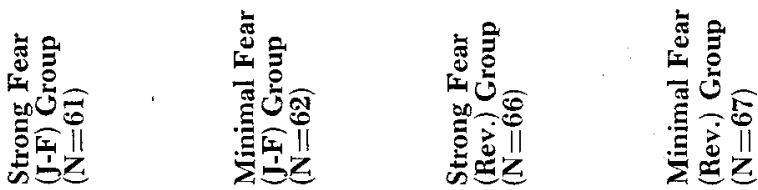

School B

$11 \%$

$9 \%$

$9 \%$

$9 \%$

$25 \%$

$8 \%$

$44 \%$

$26 \%$

For School A: All comparisons non-significant by inspection

For School B: Strong Fear Groups combined greater than Minimal Fear groups combined, $\mathrm{X}^{2}=5.13$, $\mathrm{P}$ less than $.05,1$ d.f.

TABLE 5

Conformity to Recommended Dental Hygiene Practices as a Function of Social Status Level

Summary of Analysis of Variance

\section{Variable}

A) Social Status ( 3 subgroups)

B) Strong vs. Minimal Fear

C) Interaction between Social Status and Fear Level
F-ratio

*

3.26
P-value

less than $.05,2$ and 198 d.f.

" F' not computed due to presence of significant interaction involving this variable.

\section{Bibliography}

1. Galdston, Iago. Health education, yesterday and today. p. 3-9. (In New York Academy of Medicine. Eastern States Health Education Conference; Motivation in Health Education. Proceedings. New York, Columbia University Press, 1948. 53p.)

2. Janis, I. L., and Feshbach, Seymour. Effects of fear-arousing communications. J. Abnormal Soc. Psychol., 48:78-92, 1953.

3. Goldstein, M. J. The relationship between coping and avoiding behavior and response to fear-arousing propaganda. J. Abnomal Soc. Psychol., 58:247-52, 1959.

4. Haefner, D. P. Some effects of guilt-arousing and fear-arousing persuasive communications on opinion change. Abstr. Amer. Psychol., 11:359, Aug. 1956.

5. Janis, I. L., and Terwilliger, R. F. An experimental studly of psychological resistance to fear-arousing communication. J. Abnormal Soc. Psychol., 63:403-10, 1962.

6. Leventhal, Howard, and Jacobs, R. Negative emotions and persuasion. New Haven, Yale University, 1963. nimeographed.

7. Leventhal, Howard, and Niles, Patricia. A field experiment on fear-arousal with data on the validity of questionnaire measures. J. Personality, 32:459-79, 1964.

8. Radelfinger, S. F. Some effects of fear-arousing communications on preventive health behavior. Palo Alto, Stanford University, School of Education, 1963. 135 p. thesis.

y. Young, Marjorie A. C., et al. Methods and materials in health education (communication). p. 63-94. (In Health education monographs, Supplement No. 1., 1963. 113 p.)

10. Feshbach, Seymour. The consequences of fear-arousal in public health education. Paper presented to the Massachusetts Public Health Association, Boston, Jan. 26, 1960.

11. Riessman, Leonard. Class in American society. Glencoe, Ill., The Free Press, 1959. 436 p.

12. Rosenstuck, I.M., Hochbaum, (;. M., and Kegeles, S. S. Determinants of health behavior. (Presented in Proc. Golden Anniversary White House Conference on Children and Youth. Washington, Mar. 27-Apr. 3, 1960. 429 p.) 